\title{
Fungos Antagonistas a Sclerotinia sclerotiorum em Pepineiro Cultivado em Estufa*
}

\author{
Luciana Z. Ethur ${ }^{1}$, Elena Blume ${ }^{1}$, Marlove Muniz ${ }^{1}$, Antonio Carlos F. da Silva ${ }^{2}$, Daniela R. Stefanelo ${ }^{1}$ \\ \& Edileusa K. da Rocha ${ }^{1 * *}$
}

Universidade Federal de Santa Maria, ${ }^{1}$ Departamento de Defesa Fitossanitária, ${ }^{2}$ Departamento de Biologia, CEP 97105-900, Santa Maria, RS, fax: (55) 220-8015, e-mail: eblume@smail.ufsm.br

(Aceito para publicação em 30/11/2004)

Autor para correspondência: Elena Blume

ETHUR, L.Z., BLUME, E., MUNIZ, M., DA SILVA, A.C.F., STEFANELO, D.R. \& DA ROCHA, E.K. Fungos antagonistas a Sclerotinia sclerotiorum em pepineiro cultivado em estufa. Fitopatologia Brasileira 30:127-133. 2005.

\section{RESUMO}

O mofo branco causado por Sclerotinia sclerotiorum pode inviabilizar o cultivo de olerícolas em ambiente protegido. Para elaborar-se um programa de controle biológico desse patógeno, necessita-se de antagonistas adequados. Este trabalho objetivou selecionar antagonistas fúngicos eficazes no controle de S. sclerotiorum em pepineiro (Cucumis sativus) cultivado em estufa, bem como, analisar a interferência dos antagonistas no crescimento vegetal. Foram utilizados um isolado de $S$. sclerotiorum obtido de pepineiro e 112 isolados fúngicos de quatro gêneros: Trichoderma, Fusarium, Penicillium e Aspergillus. Em experimento in vitro, foi utilizada a técnica do papel celofane e selecionados oito isolados de Trichoderma virens, os quais promoveram maior inibição no crescimento do patógeno (94 a 100\%). Dois experimentos in vivo foram desenvolvidos em estufa utilizando-se substrato autoclavado e não autoclavado, em copos plásticos, e substrato não autoclavado, em sacos plásticos; o substrato foi infestado com S. sclerotiorum e foram utilizados oito isolados de $T$. virens como antagonistas. Todos os isolados testados controlaram o tombamento de mudas, mas o efeito sobre o crescimento vegetal variou de acordo com os isolados e o tratamento do substrato.

Palavras-chave adicionais: biocontrole, solo autoclavado, Trichoderma virens, crescimento vegetal, Cucumis sativus.

\begin{abstract}
Fungi antagonic to Sclerotinia sclerotiorum on cucumber grown in greenhouse

White mold caused by Sclerotinia sclerotiorum may severely damage vegetables grown in greenhouses. To develop a biological control program for this pathogen proper antagonists are needed. This work aimed to select efficient fungi antagonists for controlling S. sclerotiorum on cucumber (Cucumis sativus) grown in greenhouses, and to evaluate the effect of the antagonist on the growth of the vegetable. An isolate of $S$. sclerotiorum obtained from cucumber and 112 fungi isolates belonging to four genera were used: Trichoderma, Fusarium, Penicillium, and Aspergillus. For the in vitro experiment, the cellophane method was used and eight Trichoderma virens isolates were selected that had inhibited the pathogen growth by 94 to $100 \%$. Greenhouse experiments used sterilized and non-sterilized substrate in plastic cups and non-sterilized substrate in plastic bags. The substrate was inoculated with $S$. sclerotiorum and the eight isolates of $T$. virens were used as antagonists. All eight isolates controlled damping-off of plants caused by S. sclerotiorum, but the effect on cucumber growth varied according to the isolate and the substrate treatment.
\end{abstract}

Additional keywords: biocontrol, autoclaved soil, Trichoderma virens, Cucumis sativus.

\section{INTRODUÇÃO}

O pepineiro (Cucumis sativus L.) é uma das hortaliças mais cultivadas em estufa no Rio Grande do Sul, existindo uma gama de doenças que se desenvolvem na cultura em ambiente protegido. Entre essas doenças, está o mofo branco causado pelo fungo Sclerotinia sclerotiorum (Lib.) de Bary, um dos problemas encontrado no cultivo do pepineiro, principalmente em estufa (Cardoso, 1994). Além disso, os cultivos em ambiente protegido sucedem-se de maneira contínua e as culturas utilizadas são, geralmente, suscetíveis

\footnotetext{
* Parte da dissertação de mestrado do primeiro autor. Trabalho financiado pela FAPERGS.

** Bolsista FAPERGS.
}

a esse fungo polífago (Purdy, 1979).

Sclerotinia sclerotiorum pode permanecer no solo na forma de escleródios e, a partir destes, produzir germinação carpogênica ou miceliogênica (Purdy, 1979). A germinação miceliogênica causa o tombamento de pré e pós-emergência e a carpogênica o desenvolvimento do mofo branco na parte aérea.

A incidência do mofo branco é favorecida pela alta densidade de plantio, períodos prolongados de precipitação, elevada umidade do ar e temperaturas amenas (Purdy, 1979; Illipronti \& Machado, 1993). Em virtude de problemas como a falta de resistência varietal a $S$. sclerotiorum (Li et al., 2003), a resistência a fungicidas por populações de $S$. sclerotiorum (Gossen et al., 2001), e o acúmulo de resíduos 


\section{L.Z. Ethur et al.}

desses produtos no meio ambiente, especialmente em cultivos protegidos, o controle biológico se apresenta como um método alternativo para o controle do S. sclerotiorum.

Alguns fungos foram relatados como importantes agentes de biocontrole de S. sclerotiorum tais como Coniothyrium minitans Campbell (Huang et al., 2000; Li et al., 2003), Gliocladium roseum Bainier (Hannusch \& Boland, 1996), Trichoderma virens (Miller, Giddens \& Foster) von Arx (Huang et al., 2000) T. viride Pers. Ex Fr. (Hannusch \& Boland, 1996), T. harzianum Rifai (Illipronti \& Machado, 1993; Menendez \& Godeas, 1998); T. hamatum (Bon.) Bainer (Illipronti \& Machado, 1993); Talaromyces flavus (Klöcker) A. C. Stock \& R. A. Sansom (Melo, 1998; Huang et al., 2000); Ulocladium atrum Preuss (Li et al., 2003) Penicillium spp. (Rai \& Saxena, 1975; Zazzerini \& Tosi, 1985); Fusarium solani (Mart) Sacc. (Illipronti \& Machado, 1993) e Fusarium spp. (Zazzerini \& Tosi, 1985).

Estudos relacionados ao biocontrole de $S$. sclerotiorum têm enfocado principalmente a degradação de escleródios, sem um direcionamento à moléstia causada pelo patógeno, especialmente em pepineiro cultivado em ambiente protegido. Portanto, o objetivo deste trabalho foi isolar e selecionar antagonistas fúngicos eficazes no controle de $S$. sclerotiorum em pepineiro cultivado em estufa, bem como, analisar a interferência dos antagonistas no desenvolvimento vegetal.

\section{MATERIAL E MÉTODOS}

\section{Isolamento dos possíveis antagonistas fúngicos}

A metodologia empregada para o isolamento foi o método de iscas (Ghini, 1989), com a utilização dos escleródios de S. sclerotiorum (Hoes \& Huang, 1975; Illipronti \& Machado, 1993; Nasser et al., 1994). Amostras de $500 \mathrm{~g}$ de solo foram retiradas da profundidade de até $10 \mathrm{~cm}$, em quatro áreas: estufa, horta, lavoura e jardim, localizadas no município de Santa Maria - RS. Quatrocentos gramas de solo de cada local foram colocados em copos de Becker de 11 . Foram enterradas, no solo, quatro trouxas feitas com gaze hidrófila (13 fios por $\mathrm{cm}^{2} ; 7,5 \mathrm{~cm} \times 7,5 \mathrm{~cm}$ com quatro dobras) e barbante, contendo cinco escleródios de $S$. sclerotiorum cada uma. O solo foi umedecido com $10 \mathrm{ml}$ de água destilada e esterilizada e os copos de Becker, cobertos com papel alumínio, foram mantidos em temperatura ambiente (com variação de 18 a $28^{\circ} \mathrm{C}$ ), sem a incidên cia direta da luz solar.

Após um período de 30 dias de incubação, os escleródios foram retirados das trouxas e imersos, por cerca de $1 \mathrm{~min}$, em álcool $(70 \%)$ e, posteriormente, em hipoclorito de sódio $(0,5 \%)$. Foram imersos três vezes em água destilada e esterilizada, deixados para secar sobre papel-filtro esterilizado e colocados em placas de Petri com meio de cultura batata-dextrose-ágar (BDA ) e mantidos a $22^{\circ} \mathrm{C}$, com fotoperíodo de $12 \mathrm{~h}$.

Os fungos encontrados nos escleródios foram repicados para placas de Petri, que continham meio BDA e deixados em câmara climatizada a $22^{\circ} \mathrm{C}$, com fotoperíodo de $12 \mathrm{~h}$. A identificação, em nível de gênero, foi feita através de microscópio estereoscópico e ótico, com base em bibliografia especializada (Barnett \& Hunter, 1998).

\section{Experimentos in vitro}

Seleção de agentes de biocontrole produtores de metabólitos não-voláteis - Utilizou-se a técnica do papel celofane (Silva, 1997; Aparecido \& Figueiredo, 1999; Durman et al., 1999) com o objetivo de selecionar agentes biocontroladores do $S$. sclerotiorum, produtores de metabólitos não-voláteis.

Foram utilizados 112 isolados fúngicos e um tratamento testemunha apenas com o fitopatógeno, em um delineamento experimental inteiramente casualizado, com quatro repetições.

Placas de Petri contendo meio BDA foram cobertas, assepticamente, com um disco de papel celofane, esterilizado em autoclave a $120^{\circ} \mathrm{C}$, durante $30 \mathrm{~min}$, com tamanho suficiente para cobrir toda a placa e ainda sobrar $0,5 \mathrm{~cm}$ nas laterais. Um disco de meio BDA, de $12 \mathrm{~mm}$ de diâmetro, contendo micélio e esporos dos possíveis antagonistas fúngicos, crescidos em meio BDA por cinco dias, foi colocado no centro das placas, sobre o papel celofane. As placas foram incubadas em câmara climatizada a $22{ }^{\circ} \mathrm{C}$ por $48 \mathrm{~h}$ (até o micélio atingir um crescimento de dois terços da placa) quando, então, o papel celofane foi retirado juntamente com a colônia do antagonista fúngico.

Dois discos de micélio retirados das bordas de colônias de $S$. sclerotiorum, crescidos em meio BDA por sete dias, foram transferidos para bordas opostas das placas de Petri contendo os metabólitos não voláteis do possível antagonista. As placas foram incubadas a $22^{\circ} \mathrm{C}$, com fotoperíodo de $12 \mathrm{~h}$. Após cinco dias de incubação, foi observado o crescimento das colônias e medida a distância $(\mathrm{cm})$ entre os dois discos, sendo considerado $5 \mathrm{~cm}$ como o máximo de inibição, ou seja, nenhum crescimento.

Confrontação direta - Os isolados fúngicos selecionados pelo método do papel celofane foram utilizados no método de confrontação direta (Bell et al., 1982; Barros et al., 1987; Silva, 1997), no qual discos do patógeno e do antagonista são colocados em lados opostos de uma placa de Petri, para demonstrar outras formas de ação além da antibiose. Após sete dias em câmara climatizada a $22{ }^{\circ} \mathrm{C}$ foi realizada a avaliação de acordo com os critérios propostos por Bell et al. (1982) com escala de notas: 1 (antagonista cresce por toda a placa de Petri), 2 (antagonista cresce sobre $2 / 3$ da placa), 3 (antagonista e patógeno crescem até a metade da placa), 4 (patógeno cresce sobre 2/3 da placa) e 5 (patógeno cresce por toda a placa de Petri).

\section{Experimentos in vivo}

Para a avaliação do potencial de biocontrole de $S$. sclerotiorum em pepineiro, foram realizados dois experimentos utilizando-se as instalações da estufa plástica do Departamento de Defesa Fitossanitária da Universidade Federal de Santa Maria.

Para o preparo do inóculo de S. sclerotiorum, quatro 
Fungos antagonistas a Sclerotinia sclerotiorum em pepineiro cultivado em estufa...

discos de meio BDA, contendo micélio de $S$. sclerotiorum, foram colocados em frascos de Erlenmeyer de $250 \mathrm{ml}$ que continham $50 \mathrm{~g}$ de arroz previamente autoclavados durante 40 min, e levados à câmara climatizada, por quinze dias, a $20{ }^{\circ} \mathrm{C}$, com fotoperíodo de $12 \mathrm{~h}$. Nesse período o fungo colonizou todo o substrato e formou grande quantidade de escleródios.

No preparo do inóculo dos antagonistas, discos de BDA contendo micélio e esporos de oito isolados de $T$. virens foram colocados sobre $50 \mathrm{~g}$ de arroz umedecidos com $75 \mathrm{ml}$ de água destilada, em frascos de Erlenmeyer previamente autoclavados por $40 \mathrm{~min}$. Os frascos de Erlenmeyer permaneceram em câmara climatizada a $22{ }^{\circ} \mathrm{C}$, com fotoperíodo de $12 \mathrm{~h}$, por 15 dias, para a colonização do arroz. Após, ocorreu a secagem em estufa $\left(37^{\circ} \mathrm{C}\right)$ e o inóculo foi triturado em liquidificador até ser transformado em pó e passado por uma peneira de 40 meshes.

As sementes de pepino utilizadas nos experimentos são da variedade caipira, para salada. As sementes não receberam qualquer tipo de tratamento anterior à semeadura.

\section{Biocontrole de $S$. sclerotiorum em pepineiro cultivado em} substrato autoclavado e não autoclavado - Os tratamentos foram dispostos em um delineamento inteiramente casualizado, com quatro repetições, em esquema fatorial 9 x 2 × 2 (isolados de Trichoderma - TE4, TE8, TH1, TH7, TH10, TH12, TH15 e TH17 + testemunha) x (presença e ausência de $S$. sclerotiorum) x (substrato autoclavado e não autoclavado).

Copos plásticos, com capacidade para $500 \mathrm{ml}$, foram preenchidos com $380 \mathrm{~g}$ de substrato comercial Plantimax autoclavado $\left(2 \mathrm{~h} \mathrm{a} 120^{\circ} \mathrm{C}\right)$ e não autoclavado. Os copos com substrato autoclavado foram separados daqueles com substrato não autoclavado. $O$ fitopatógeno foi incorporado ao substrato a uma profundidade de $5 \mathrm{~cm}$, usando-se $15 \mathrm{~g}$ de inóculo. Após quatro dias, $0,5 \mathrm{~g}$ de pó biológico dos isolados de $T$. virens foi espalhado nas covas e quatro sementes de pepino foram semeadas por copo. Os tratamentos foram irrigados diariamente.

No oitavo dia após a semeadura, foi realizada a contagem do número de plântulas por copo, avaliando-se o índice de germinação. Dezoito dias depois da semeadura, foi feita a avaliação final, que constou da incidência de tombamento de pós-emergência e da medida da altura das plantas (colo até a axila da primeira folha adulta).

Biocontrole de $S$. sclerotiorum em pepineiro com diferentes isolados de $\boldsymbol{T}$. virens - Os tratamentos foram dispostos em um delineamento inteiramente casualizado, com quatro repetições, em esquema fatorial 9 × 2 (isolados de Trichoderma - TE4, TE8, TH1, TH7, TH10, TH12, TH15 e TH17 + testemunha) x (presença e ausência de $S$. sclerotiorum).

Sacos plásticos com capacidade para $1,5 \mathrm{~kg}$ foram preenchidos com $1 \mathrm{~kg}$ de substrato comercial Plantimax e dispostos em seis fileiras sobre camalhões na estufa. O fitopatógeno foi incorporado ao substrato a uma profundidade de $5 \mathrm{~cm}$, usando-se $30 \mathrm{~g}$ de inóculo. Após quatro dias, $1 \mathrm{~g}$ de pó biológico dos isolados de $T$. virens foi espalhado nas covas e quatro sementes de pepino foram semeadas por saco. Os tratamentos foram irrigados diariamente.

No sexto dia após a semeadura, foi realizada a avaliação da germinação, contando-se o número de plântulas por saco. Depois de 20 dias da semeadura, foi feita a avaliação final do experimento, quanto à incidência de tombamento, o crescimento (medida do colo até a axila da primeira folha verdadeira) e massa seca da raiz, parte aérea e total das plantas.

\section{Análise estatística}

Foi realizada análise de variância de todos os experimentos, sendo as médias comparadas pelo teste de Duncan, a 5\% de probabilidade. Para a análise dos resultados do teste do papel celofane os dados foram transformados em "raiz $(\mathrm{X}+1)$ ".

\section{RESULTADOS}

\section{Possíveis antagonistas fúngicos}

Com a utilização dos escleródios como iscas, retirouse do solo um total de cento e doze isolados de possíveis antagonistas fúngicos, de quatro gêneros: Trichoderma, Fusarium, Aspergillus e Penicillium.

Dos quatro gêneros de fungos encontrados no solo, nos quatro diferentes locais de coleta (horta, jardim, lavoura e estufa) Trichoderma apresentou maior número de isolados, com 73, em segundo Penicillium, com 33, seguidos por Fusarium e Aspergillus, com três isolados cada.

Trichoderma spp. foi encontrado nos quatro locais de coleta, em maior quantidade de isolados no solo de lavoura $(31,50 \%)$, seguido pelo de horta $(27,40 \%)$, de jardim $(24,66 \%)$ e de estufa $(16,44 \%)$.

\section{Experimentos in vitro}

Dos 112 isolados fúngicos iniciais, sobressaíram-se 17 do gênero Trichoderma, demonstrando o melhor desempenho deste gênero no teste in vitro. Os isolados de Penicillium spp. (inibição de 0 a $48 \%$ e um isolado com $77 \%$ ), Aspergillus spp. (inibição de 0 a 1,4\%) e Fusarium spp. (inibição de 0 a $2,4 \%$ ) não mostraram bons desempenhos quando comparados aos isolados de Trichoderma spp. (Tabela 1).

A variabilidade entre isolados de Trichoderma é evidente, pois dos 73 isolados obtidos, oito (11\%) não apresentaram qualquer inibição no crescimento micelial do fitopatógeno. Os demais isolados (89\%) apresentaram índices variados de inibição micelial de $S$. sclerotiorum.

Dos 17 melhores isolados de Trichoderma spp., oito foram selecionados demonstrando os seguintes percentuais de inibição do crescimento micelial de S. sclerotiorum: 97,8\% para TH12 e TH1; 97,8\% para TE4 e TE8; 96,4\% para TH10; 95,8\% para TH7 e TH17; 95,4\% para TH15 (Tabela 1). Os isolados de Trichoderma spp. com melhor desempenho em antibiose foram os retirados do solo de horta e de estufa. 
A eficácia in vitro dos oito isolados antagonistas selecionados na técnica do papel celofane foi confirmada na técnica de confrontação direta com S. sclerotiorum, pois todos os isolados obtiveram nota 5 (100\% de controle), demonstrando que os mesmos possuem outras habilidades no biocontrole do fitopatógeno, além da antibiose. Pode-se ressaltar que todos os escleródios formados pelo fitopatógeno foram parasitados pelos isolados de Trichoderma, apresentando modificações na consistência (amolecimento) e perda de viabilidade.

Os oito isolados de Trichoderma spp. selecionados nos testes in vitro, foram identificados com auxílio de microscópio estereoscópico e ótico, considerando-se a coloração da colônia (em meio BDA) e a morfologia dos conidióforos, fiálides e conídios, com base na descrição de Bisset (1991), como Trichoderma (Gliocladium) virens (Miller, Giddens, and Foster) von Arx.

\section{Biocontrole de $S$. sclerotiorum em pepineiro cultivado em substrato autoclavado e não autoclavado}

Quanto à germinação das sementes de pepino, não houve interação entre os três fatores: isolados de Trichoderma virens, presença ou ausência do fitopatógeno e autoclavagem ou não do substrato. Encontrou-se significância apenas com relação à presença ou ausência de $S$. sclerotiorum. A emergência em tratamentos com S. sclerotiorum foi menor $(47 \%)$ do que nos tratamentos sem o fitopatógeno $(85 \%)$.

O tombamento de mudas foi de apenas $7,7 \%$ no tratamento testemunha, com $S$. sclerotiorum, em substrato não autoclavado. No restante, tanto em substrato autoclavado como não autoclavado não ocorreu tombamento de pósemergência.

Quanto à altura do pepineiro, o resultado da análise de variância mostrou interação significativa entre os três fatores: isolados de $T$. virens, presença ou ausência de $S$. sclerotiorum e autoclavagem ou não do substrato. Encontraram-se diferenças significativas no crescimento do pepineiro com os diferentes isolados de $T$. virens em substrato autoclavado e não autoclavado, na presença ou ausência de S. sclerotiorum. Com exceção do substrato não autoclavado e inoculado com S. sclerotiorum, as plantas dos demais tratamentos tratadas com o isolado TH7 apresentaram a maior altura, embora, por vezes, não significativamente diferente da testemunha ou de outros isolados. Por outro

TABELA 1 - Antagonismo in vitro, pelo teste do papel celofane, de diferentes isolados de fungos a Sclerotinia sclerotiorum. Santa Maria, RS

\begin{tabular}{|c|c|c|c|c|c|}
\hline Antagonista* & Inibição $(\mathrm{cm}) * *$ & Antagonista* & Inibição $(\mathrm{cm}) * *$ & Antagonista* & Inibição $(\mathrm{cm}) * *$ \\
\hline TH12 & $4,89 a^{* * *}$ & TJ2 & 3,54 fghijk & TH8 & $1,84 \mathrm{rst}$ \\
\hline TH1 & $4,89 \mathrm{a}$ & TL2 & 3,49ghijk & TL12 & $1,56 \mathrm{stu}$ \\
\hline TE4 & $4,89 \mathrm{a}$ & TL7 & $3,46 \mathrm{hijk}$ & TH9 & 1,49 tu \\
\hline TE8 & $4,89 \mathrm{a}$ & $\mathrm{TJ} 14$ & 3,34hijkl & TL18 & 1,42 tuv \\
\hline TH10 & $4,82 \mathrm{ab}$ & TJ5 & 3,31 hijkl & TH4 & 1,40 tuv \\
\hline TH7 & $4,79 \mathrm{ab}$ & TJ10 & 3,29hijkl & TL19 & $1,20 u v w$ \\
\hline TH17 & $4,79 \mathrm{ab}$ & TL8 & $3,12 \mathrm{ijklm}$ & PH5 & 1,11 uvwx \\
\hline TH15 & $4,77 \mathrm{ab}$ & TJ17 & $3,11 \mathrm{ijklm}$ & TL11 & 1,11 uvwx \\
\hline TH16 & $4,62 \mathrm{abc}$ & TL14 & $3,11 \mathrm{ijklm}$ & TL9 & 1,07 uvwx \\
\hline TJ6 & $4,53 \mathrm{abcd}$ & $\mathrm{TJ} 12$ & $3,05 \mathrm{jklmn}$ & TJ8 & 1,05 uvwx \\
\hline TE3 & $4,52 \mathrm{abcd}$ & TL5 & $2,86 \mathrm{klmno}$ & TJ15 & $0,95 \mathrm{vwx}$ \\
\hline $\mathrm{TH} 2$ & $4,52 \mathrm{abcd}$ & TE2 & $2,751 \mathrm{mnop}$ & $\mathrm{TJ} 4$ & $0,79 w x y$ \\
\hline TH14 & $4,49 \mathrm{abcd}$ & TL17 & 2,731mnop & TH5 & $0,71 x y z$ \\
\hline TE12 & 4,49 abcd & TH19 & $2,721 \mathrm{mnop}$ & TH3 & $0,44 \mathrm{yz}$ \\
\hline TE11 & 4,39abcde & TL23 & $2,52 \mathrm{mnopq}$ & TL6 & $0,36 z$ \\
\hline TL21 & 4,29abcdef & TL4 & 2,47 mnopqr & TL20 & $0,30 \mathrm{z}$ \\
\hline TE7 & 4,24abcdefg & TE9 & 2,46 mnopqr & TE1 & $0,24 z$ \\
\hline TJ11 & 3,99 bcdefgh & TH6 & 2,42 nopqr & PE7 & $0,19 \mathrm{z}$ \\
\hline TJ18 & 3,89 cdefgh & $\mathrm{PJ} 3$ & 2,39 nopqr & FE1 & $0,12 z$ \\
\hline PH1 & 3,86cdefghi & TE5 & 2,38 nopqr & $\mathrm{TJ} 3$ & $0,12 z$ \\
\hline TH13 & 3,74defghij & TE10 & 2,28 opqr & PJ4 & $0,11 z$ \\
\hline TL10 & 3,68efghij & TH18 & 2,11 pqrs & PL3 & $0,09 z$ \\
\hline TL15 & 3,61 fghij & TE6 & 1,96 qrst & $\mathrm{AJ} 2$ & $0,07 \mathrm{z}$ \\
\hline TJ1 & 3,57fghijk & TJ16 & $1,94 \mathrm{qrst}$ & PH11 & $0,07 \mathrm{z}$ \\
\hline \multirow[t]{2}{*}{ TL1 } & 3,54 fghijk & TL13 & $1,93 \mathrm{qrst}$ & TESTEM & $0,00 \mathrm{z}$ \\
\hline & & & & $\& * * * *$ & $0,00 \mathrm{z}$ \\
\hline
\end{tabular}

*PH - Penicillium spp. Horta; TH - Trichoderma spp. Horta; PJ - Penicillium spp. Jardim; TJ - Trichoderma spp. Jardim; AJ - Aspergillus spp. Jardim; PL - Penicillium spp. Lavoura;TL - Trichoderma spp. Lavoura; PE - Penicillium spp. Estufa; TE - Trichoderma spp. Estufa; FE - Fusarium spp. Estufa.

** Distância (cm) entre as bordas de dois micélios de $S$. sclerotiorum colocados em bordas opostas na placa de Petri.

*** Médias seguidas com mesma letra não diferem entre si pelo Teste de Duncan a 5\% de probabilidade.

**** Foram suprimidos 38 isolados por apresentarem a mesma média da testemunha. 
Fungos antagonistas a Sclerotinia sclerotiorum em pepineiro cultivado em estufa...

lado, alguns isolados reduziram a altura de plantas, como o isolado TH15, exceto no substrato autoclavado com $S$. sclerotiorum (Tabela 2).

De um modo geral, na presença de $S$. sclerotiorum, as plantas apresentaram menor crescimento do que na ausência do fitopatógeno, tanto em substrato autoclavado como em substrato não autoclavado, embora não apresentassem sintoma de mofo branco. A autoclavagem do substrato interferiu positivamente no crescimento das plantas (Tabela 2).

\section{Biocontrole de $S$. sclerotiorum em pepineiro com diferentes isolados de $T$. virens}

Quanto à germinação, não houve diferenças significativas entre os diferentes isolados de $T$. virens na ausência ou presença de $S$. sclerotiorum.

Quanto ao tombamento de pós-emergência, nenhum dos tratamentos com $T$. virens apresentou a doença, enquanto que a testemunha, com S. sclerotiorum, apresentou $20 \%$ de "damping-off".

Não houve diferença significativa entre os diferentes isolados de $T$. virens, mas observou-se menor altura de plantas na presença $(5,27 \mathrm{~cm})$ do que na ausência $(7,59 \mathrm{~cm})$ do fitopatógeno, confirmando os resultados do experimento anterior.

Quanto à massa seca das plantas, não se encontraram diferenças significativas entre os diferentes isolados de $T$. virens, mas tratamentos sem $S$. sclerotiorum apresentaram a maior massa seca de raízes, parte aérea e total (Tabela 3).

\section{DISCUSSÃO}

Pelo método de iscas obtiveram-se quatro gêneros fúngicos (Trichoderma, Fusarium, Aspergillus e Penicillium), sendo que estes já haviam sido anteriormente encontrados parasitando escleródios de $S$. sclerotiorum, tais como: T. viride (Nasser et al., 1994), T. koningii Oudemans (Illipronti \& Machado, 1993; Nasser et al., 1994), T. harzianum, T. hamatum e T. polisporum (Link : Fr.) Rifai (Illipronti \& Machado, 1993); Fusarium spp. (Jones \& Watson, 1969; Hoes \& Huang, 1975), F. merismoides Corda, $F$. graminearum Schwabe, F. lateritium Ness : Fries, $F$. episphaeria (Tode) WC Snyder \& HN Hans (Nasser et al., 1994) e F. solani (Martius) Saccardo (Illipronti \& Machado, 1993); Aspergillus flavus Link : Fr. e A. sydowii (Bainier \& Sartori) Thom \& Church (Illipronti \& Machado, 1993; Nasser et al., 1994); Penicillium spp. (Adams \& Ayers, 1979).

Pode-se observar que, embora os diferentes isolados fúngicos tenham sido retirados dos escleródios de $S$. sclerotiorum, apenas alguns foram selecionados no teste de antibiose como potenciais agentes de biocontrole do fitopatógeno.

$\mathrm{Na}$ seleção in vitro, os melhores isolados fúngicos foram do gênero Trichoderma o que vem ao encontro dos resultados apresentados por Zazzerini \& Tosi (1985) em pesquisa de seleção de isolados fúngicos ao S. sclerotiorum.
A eficácia de isolados de Trichoderma com relação ao fitopatógeno $S$. sclerotiorum na técnica do papel celofane foi demonstrada por Silva (1997), o qual observou que isolados de $T$. viride e $T$. harzianum foram efetivos quanto à inibição micelial do referido patógeno (80 a 100\%). O mesmo foi encontrado por Ethur et al. (2001) onde foram selecionados quatro de 12 isolados de Trichoderma spp. que inibiram o crescimento micelial de S. sclerotiorum de 95 a $100 \%$.

A efetividade de Trichoderma spp. sobre $S$. sclerotiorum, utilizando-se a técnica de confrontação direta, foi demonstrada anteriormente (Zazzerini \& Tosi, 1985; Barros et al., 1987; Silva, 1997; Ethur et al., 2001), sem, no entanto, haver menção à espécie em estudo. No confronto direto do agente de biocontrole com o fitopatógeno, além da antibiose já observada no teste do papel celofane, devem ter ocorrido outras ações antagônicas, como o hiperparasitismo e a competição.

Os isolados de $T$. virens selecionados nos testes in vitro foram efetivos quanto ao tombamento de mudas causado por S. sclerotiorum, o qual é um patógeno causador de "damping-off" de pré e pós-emergência em muitas culturas, inclusive no pepineiro (Cardoso, 1994). Em casa de vegetação, Menendez \& Godeas (1998) observaram que na

TABELA 2 - Altura (cm) das plantas de pepineiro (Cucumus sativus) (cm) em substratos autoclavado e não autoclavado, na ausência ou presença de Sclerotina sclerotiorum, em tratamentos com diferentes isolados de Trichoderma virens. Santa Maria, RS

\begin{tabular}{|c|c|c|c|c|}
\hline \multirow{3}{*}{$\begin{array}{l}\text { Isolado de } \\
\text { Trichoderma } \\
\text { virens }\end{array}$} & \multirow{2}{*}{\multicolumn{2}{|c|}{$\begin{array}{c}\text { Subst. autoclavado } \\
\text { Sclerotinia sclerotiorum } \\
\end{array}$}} & \multirow{2}{*}{\multicolumn{2}{|c|}{$\begin{array}{l}\text { Subst. não autoclavado } \\
\text { Sclerotinia sclerotiorum }\end{array}$}} \\
\hline & & & & \\
\hline & Ausência & Presença & Ausência & Presença \\
\hline Testemunha & $9,12 \mathrm{ab} \mathrm{A} *$ & $4,68 \mathrm{~b} \mathrm{~B}$ & $6,67 \mathrm{~b} \mathrm{~A}$ & 5,07 a B \\
\hline TH1 & 7,59 bc A & $4,07 \mathrm{bc} \mathrm{B}$ & $6,67 \mathrm{~b} \mathrm{~A}$ & $3,08 \mathrm{~b}$ B \\
\hline TH7 & 9,16 a $\mathrm{A}$ & $6.41 \mathrm{a} B$ & 7,64 a A & $2,72 \mathrm{~b} \mathrm{~B}$ \\
\hline TH10 & $8,61 \mathrm{ab} A$ & $3.91 \mathrm{bc} \mathrm{B}$ & $3,04 \mathrm{c} \mathrm{A}$ & $2,92 \mathrm{~b} \mathrm{~A}$ \\
\hline TH12 & 7,64 abc $A$ & 5.92 a B & $3,25 \mathrm{c} \mathrm{A}$ & $3,08 \mathrm{~b}$ A \\
\hline TH15 & $6,47 \mathrm{c} \quad \mathrm{A}$ & 5.77 a B & $3,38 \mathrm{c} \mathrm{A}$ & $1,37 \mathrm{~d} B$ \\
\hline TH17 & 7,78 abc A & $2.89 \mathrm{~d} \mathrm{~B}$ & $3,66 \mathrm{c} \mathrm{A}$ & $2,09 \mathrm{cB}$ \\
\hline TE4 & $8,87 \mathrm{ab} A$ & $3.55 \mathrm{~cd} \mathrm{~B}$ & $6,83 \mathrm{~b} \mathrm{~A}$ & $2,60 \mathrm{bc} \mathrm{B}$ \\
\hline TE8 & $8,22 \mathrm{ab} A$ & $4.79 \mathrm{~b} \mathrm{~B}$ & $6,37 \mathrm{~b} \mathrm{~A}$ & $2,57 \mathrm{bc} B$ \\
\hline
\end{tabular}

* Médias seguidas pela mesma letra minúscula na coluna e pela mesma letra maiúscula na linha, dentro de substrato autoclavado e não autoclavado, não diferem significativamente entre si pelo teste de Duncan a $5 \%$ de probabilidade.

TABELA 3 - Massa seca de raiz, parte aérea e total (g), dos pepineiros (Cucumis sativus), na presença ou ausência de Sclerotinia sclerotiorum. Santa Maria, RS

\begin{tabular}{lccc}
\hline \hline \multirow{2}{*}{ Sclerotinia sclerotiorum } & \multicolumn{3}{c}{ Massa seca $(\mathrm{g})$} \\
\cline { 2 - 4 } & Raiz & Parte aérea & Total \\
\hline Ausência & $0,037 \mathrm{a}^{*}$ & $0,167 \mathrm{a}$ & $0,197 \mathrm{a}$ \\
Presença & $0,026 \mathrm{~b}$ & $0,096 \mathrm{~b}$ & $0,118 \mathrm{~b}$ \\
\hline
\end{tabular}

*Médias seguidas pela mesma letra minúscula, não diferem significativamente entre si pelo teste de Duncan a 5\% de probabilidade. 
presença de T. harzianum o tombamento de mudas de soja [Glyxine $\max$ (L.) Merril] causado por $S$. sclerotiorum foi de $20 \%$, enquanto na ausência deste o tombamento foi de $60 \%$. Já Huang et al. (2000) observaram controle de 16 a $30 \%$ de S. sclerotiorum em plântulas de girassol (Helianthus annuus L.), por um isolado de T. virens.

A ação de isolados de $T$. virens contra patógenos de solo ocorre de acordo com Wilhite et al. (2001) devido a interações antagônicas, dentre elas, a liberação do antibiótico gliotoxin (antibiose) e sideróforos para a aquisição de ferro (competição). Trichoderma virens é efetivo contra "dampingoff" causado por S. sclerotiorum (Huang et al., 2000) e Pythium ultimum e Rhizoctonia solani Kühn (Lumsden \& Locke, 1989), mas não há constatações dessa espécie controlando "damping-off" em pepineiro no Brasil.

Com relação aos agentes de biocontrole, além da efetividade quanto ao controle do fitopatógeno, precisa-se levar em consideração alguns fatores como a sua interferência no crescimento e/ou desenvolvimento das plantas. Nesse trabalho, alguns isolados de $T$. virens utilizados não interferiram no crescimento dos pepineiros, e outros interferiram negativa ou positivamente no primeiro experimento, mas o mesmo não se confirmou no segundo, no qual nenhum isolado interferiu no desenvolvimento das plantas. Melo (1996), utilizando duas linhagens mutantes de $T$. koningii hiperprodutoras de celulase e antagônicas a $S$. sclerotiorum, observou aumento na emergência e no peso seco dos pepineiros.

A variabilidade entre os isolados de Trichoderma spp., quanto a interferência no crescimento de vegetais, consiste, principalmente, na produção de metabólitos secundários e na sua capacidade de ser competitivo na rizosfera. Ousley et al. (1993) demonstraram esta variabilidade quando utilizaram um isolado de Trichoderma produtor de viridiol que interferiu negativamente na germinação de alface (Lactuca sativa L.) e outros isolados produtores de ácidos graxos e glicerol que atuaram positivamente no crescimento de trigo (Triticum aestivum L.). Além da variabilidade entre isolados de Trichoderma spp., pode-se encontrar, também, diferenças na ação destes, dependendo da temperatura, umidade e tipo de solo.

Observou-se que o crescimento das plantas, no geral, foi maior em substrato autoclavado, podendo ser devido à modificação química ocorrida pela esterilização do mesmo. Do mesmo modo, Windham et al. (1986) encontraram aumento na emergência de plântulas de tomate (Lycopersicon esculentum Mill.) e fumo (Nicotiana tabacum L.) em solo autoclavado, assim como de peso seco de raiz e parte aérea.

O controle biológico, através da introdução de antagonistas, pode ser considerado uma alternativa viável para o controle de fungos de solo como S. sclerotiorum. Isolados de Trichoderma spp. selecionados em testes in vitro e in vivo são considerados excelentes agentes de biocontrole e possuem a vantagem de serem inócuos ao ser humano (Melo, 1996) e não causarem impacto negativo no meio ambiente (Patricio et al., 2001).

\section{REFERÊNCIAS BIBLIOGRÁFICAS}

ADAMS, P.B. \& AYERS, W.A. Ecology of Sclerotinia species. Phytopathology 69:896-899. 1979.

APARECIDO, C.C. \& FIGUEIREDO, M.B. Antagonismo de Trichoderma viride a dois diferentes fungos de solo patogênicos ao feijão (Phaseolus vulgaris). Biológico 61:17-21. 1999.

BARNETT, H.L. \& HUNTER, B.B. Ilustrated genera of imperfect fungi. Third edition. Minnesota. Burgess Publishing Company. 1998.

BARROS, I.B.I., COSTA, C.P. \& MELO, I..S. Avaliação do potencial antagônico de Trichoderma sp. em relação a Sclerotinia minor. Anais, $3^{\text {a }}$ Reunião Anual sobre Controle Biológico de Doenças de Plantas, São Paulo, SP. 1987.

BELL, D.K., WELLS, H.D. \& MARKHAM, C.R. In vitro antagonism of Trichoderma species against six fungal plant pathogens. Phytopathology 72:379-382. 1982.

BISSET, J. A revision of the genus Trichoderma III. Section Pachybasium. Canadian Journal of Botany 69:2373-2417. 1991.

CARDOSO, J.E. Mofo branco. In: Sartorato, A. \& Rava, C.A. (Eds.) Principais doenças do feijoeiro comum e seu controle. Brasília. EMBRAPA-SPI. 1994. pp.111-122.

DURMAN, S., MENENDEZ, A. \& GODEAS, A. Evaluación de Trichoderma spp. como antagonista de Rhizoctonia solani in vitro y como biocontrolador del damping-off de plantas de tomate en invernadeiro. Revista Argentina de Microbiologia 31:13-18. 1999.

ETHUR, L.Z., CEMBRANEL, C.Z. \& SILVA, A.C.F. Seleção de Trichoderma spp. visando o controle de Sclerotinia sclerotiorum, in vitro. Ciência Rural 31:885-887. 2001.

GHINI, R. Método de iscas para obtenção de isolados de Trichoderma antagônicos a Botrytis cinerea. Jaguariúna. EMBRAPA-CNPDA. 1989.

GOSSEN, B.D., RIMMER, S.R. \& HOLLEY, J.D. First report of resistance to benomyl fungicide in Sclerotinia sclerotiorum. Plant Disease 85:1206. 2001. (Note).

HANNUSCH, D.J. \& BOLAND, G.J. Influence of air temperature and relative humidity on biological control of White mold of bean (Sclerotinia sclerotiorum). Phytopathology 86:156-162. 1996.

HOES, J.A. \& HUANG, H.C. Sclerotinia sclerotiorum: viability and separation of sclerotia from soil. Phytopathology 65:1431-1432. 1975.

HUANG, H.C., BREMER, E., HYNES, R.K. \& ERICKSON, R.S. Foliar application of fungal biocontrole agents for the control of white mold by dry bean caused by Sclerotinia sclerotiorum. Biological Control 18:270-276. 2000.

ILLIPRONTI JR., R.A. \& MACHADO, J.C. Antagonismo de fungos a Sclerotinia sclerotiorum em soja e feijão. Fitopatologia Brasileira 18:162-166. 1993.

JONES, D. \& WATSON, D. Parasitism and lysis by soil fungi of Sclerotinia sclerotiorum (Lib.) de Bary, a phytopathogenic fungus. Nature 224:287-288. 1969.

LI, G.Q., HUANG, H.C. \& ACHARYA, S.N. Antagonism and biocontrol potential of Ulocladium atrum on Sclerotinia sclerotiorum. Biological Control 28:11-18. 2003.

LUMSDEN, R.D. \& LOCKE, J.C. Biological control of dampingoff caused by Pythium ultimum and Rhizoctonia solani with Gliocladium virens in soiless mix. Phytopathology 79:361-366. 1989. 
Fungos antagonistas a Sclerotinia sclerotiorum em pepineiro cultivado em estufa...

MELO, I.S. Trichoderma e Gliocladium como bioprotetores de plantas. Revisão Anual de Patógenos de Plantas 4:261-295. 1996.

MELO, I.S. Agentes microbianos de controle de fungos fitopatogênicos. In: Melo, I.S. \& Azevedo, J.L. (Eds.) Controle biológico. Jaguariúna. EMBRAPA. 1998. pp.17-66.

MENENDEZ, A.B. \& GODEAS, A. Biological control of Sclerotinia sclerotiorum attacking soybean plants. Degradation of the cell walls of this pathogen by Trichoderma harzianum (BAFC 742). Mycopathologia 142:153-160. 1998.

NASSER, L.C.B., BARRON, G., SUTTON, J.C. \& NAPOLEÃO, R. Fungos associados com esclerócios de Sclerotinia sclerotiorum coletados em áreas de feijoeiro irrigado nos cerrados. Fitopatologia brasileira 19:331. 1994. (Resumo)

OUSLEY, M.A., LYNCH, J.M. \& WHIPPS, J.M. Effect of Trichoderma on plant growth: a balance between inhibition and growth promotion. Microbial Ecology 26:277-285. 1993.

PATRICIO, F.R.A., KIMATI, H. \& BARROS, B.C. Seleção de isolados de Trichoderma spp. antagônicos a Pythium aphanidermatum e Rhizoctonia solani. Summa Phytopathologica 27: 223-229. 2001.

PURDY, L.H. Sclerotinia sclerotiorum: history, diseases and symptomatology, host range, geographie distribution, and impact.
Phytopathology 69: 875-880. 1979.

RAI, J.N. \& SAXENA, V.C. Sclerotial mycoflora and its role in natural biological control of white rot disease. Plant and soil 43:509513. 1975.

SILVA, A.C.F. Uso de radiação gama para obtenção de mutantes de Trichoderma harzianum Rifai. e T. viride Pers. Fr. com capacidade melhorada no controle de Sclerotinia sclerotiorum (Lib.) de Bary. (Tese de Doutorado) São Paulo. Universidade de São Paulo. 1997. SILVA-RIBEIRO, R.T., TERMIGNONI, C., DILLON, A.J.P. \& HENRIQUES, J.A.P. Produção de hidrolases por cinco linhagens de Trichoderma spp. frente ao fungo fitopatogênico Botrytis cinerea, e o controle biológico da podridão do colo da alface (Lactuca sativa). Genetics and Molecular Biology 22:423.1999. (Resumo)

ZAZZERINI, A. \& TOSI, L. Antagonistic activity of fungi isolated from sclerotia of Sclerotinia sclerotiorum. Plant Pathology 34:415421. 1985.

WILHITE, S.E., LUMSDEN, R.D. \& STRANEY, D.C. Peptide synthetase gene in Trichoderma virens. Applied and Environmental Microbiology 67:5055-5062. 2001.

WINDHAM, M.T., ELAD, Y. \& BAKER, R. A mechanism for increased plant growth induced by Trichoderma spp. Phytopathology 76:518-521. 1986. 